\title{
BMJ Open Can variability in the effect of opioids on refractory breathlessness be explained by genetic factors?
}

\author{
David C Currow, ${ }^{1,2}$ Stephen Quinn, ${ }^{3}$ Magnus Ekstrom, ${ }^{1,4}$ Stein Kaasa, ${ }^{5,6}$ \\ Miriam J Johnson, ${ }^{7}$ Andrew A Somogyi, ${ }^{8}$ Päl Klepstad ${ }^{9,10}$
}

To cite: Currow DC, Quinn S, Ekstrom M, et al. Can variability in the effect of opioids on refractory breathlessness be explained by genetic factors?. BMJ Open 2015;5:e006818. doi:10.1136/bmjopen-2014006818

- Prepublication history for this paper is available online. To view these files please visit the journal online (http://dx.doi.org/10.1136/ bmjopen-2014-006818)

Received 3 October 2014 Revised 9 April 2015 Accepted 12 April 2015

CrossMark

For numbered affiliations see end of article.

Correspondence to Professor David C Currow; david.currow@flinders.edu.au

\section{ABSTRACT}

Objectives: Opioids modulate the perception of breathlessness with a considerable variation in response, with poor correlation between the required opioid dose and symptom severity. The objective of this hypothesis-generating, secondary analysis was to identify candidate single nucleotide polymorphisms (SNP) from those associated with opioid receptors, signalling or pain modulation to identify any related to intensity of breathlessness while on opioids. This can help to inform prospective studies and potentially lead to better tailoring of opioid therapy for refractory breathlessness.

Setting: 17 hospice/palliative care services (tertiary services) in 11 European countries.

Participants: 2294 people over 18 years of age on regular opioids for pain related to cancer or its treatment.

Primary outcome measures: The relationship between morphine dose, breathlessness intensity (European Organisation for Research and Treatment of Cancer Core Quality of Life Questionnaire; EORTCQLQC30 question 8) and 112 candidate SNPS from 25 genes $(n=588)$.

Secondary outcome measures: The same measures for people on oxycodone $(n=402)$ or fentanyl $(\mathrm{n}=429)$.

Results: SNPs not in Hardy-Weinberg equilibrium or with allele frequencies $(<5 \%)$ were removed. Univariate associations between each SNP and breathlessness intensity were determined with Benjamini-Hochberg false discovery rate set at $20 \%$. Multivariable ordinal logistic regression, clustering over country and adjusting for available confounders, was conducted with remaining SNPS. For univariate morphine associations, 1 variant on the 5-hydroxytryptamine type 3B (HTR3B) gene, and 4 on the $\beta$-2-arrestin gene (ARRB2) were associated with more intense breathlessness. 1 SNP remained significant in the multivariable model: people with rs7103572 SNP (HTR3B gene; present in $8.4 \%$ of the population) were three times more likely to have more intense breathlessness (OR 2.86; 95\% Cls 1.46 to $5.62 ; p=0.002)$. No associations were seen with fentanyl nor with oxycodone.

Conclusions: This large, exploratory study identified 1 biologically plausible SNP that warrants further study in the response of breathlessness to morphine therapy.

\section{Strengths and limitations of this study}

- This is the first study that seeks to identify any candidate single nucleotide polymorphisms that help to predict differences in breathlessness intensity while on morphine.

- This is a population-based study using rigorous methodologies.

- The cohort used are taken from clinical practice across a range of clinical settings and countries.

- There is no replication cohort in this study-this is a topic for further work.

- This study has only sought signal from a bank of candidate genes.

\section{INTRODUCTION}

Breathlessness that persists despite diseasemodifying treatment (refractory breathlessness) is a major clinical problem internationally. ${ }^{1}$ Chronic causes include respiratory disease (mainly chronic obstructive pulmonary disease (COPD) and interstitial lung disease), cardiac failure, progressive neurological disorders, cancers and cachexia in any late-stage disease. ${ }^{3-5}$ Symptom control is a key priority for people with a life-limiting illness as well as for their caregivers. ${ }^{6}$

Experimental studies of people with COPD and in healthy volunteers have shown that endogenous and exogenous opioids modulate the perception of breathlessness intensity without diminishing the ability to breathe during exercise or with resistive loads. ${ }^{7-9}$ In phase III clinical trials, the regular and systematic use of low doses of morphine $(\leq 30 \mathrm{mg}$ morphine $/ 24 \mathrm{~h}$ ) have been shown to safely reduce chronic refractory breathlessness intensity by a clinically meaningful extent. ${ }^{10-14}$

In the only formal dose-ranging study of opioids for the reduction of breathlessness intensity, the opioid dose needed to relieve breathlessness is highly individual, with a threefold difference of the dose required to relieve breathlessness, and where there was 
only a weak association between the severity of breathlessness and the dose of low-dose, sustained-release morphine providing relief. ${ }^{11}$ Clinicodemographic factors predicting response of breathlessness intensity to opioids from pooled data included higher baseline intensity of breathlessness and younger age. ${ }^{15}$ In this analysis, breathlessness intensity was not predicted by the dominant aetiology of breathlessness, gender, functional status nor descriptors of the breathlessness. ${ }^{15}$

Clinically, large interindividual variations are also seen in the doses of opioids required to relieve pain in the palliative care population. The European Pharmacogenetic Opioid Study (EPOS), the largest such study in the world $(\mathrm{n}=2294)$, failed to find any single nucleotide polymorphisms (SNPs) from 112 candidate SNPs on 25 genes involved in opioid receptors, signalling, nor pain-modifying functions that explained any of the variations in the opioid dose required to achieve a symptomatic response to opioids for pain. ${ }^{16}$ This was in contrast with smaller studies which had identified several SNPs purportedly influencing the dose-response relationship. ${ }^{16}$ To date, no studies exploring genetic variability related to opioids and the palliation of refractory breathlessness have been conducted.

The aim of this hypothesis-generating, secondary analysis of the EPOS data is to identify possible candidate SNPs from a selection identified in the literature known to be associated with opioid pharmacology in order to inform future and prospective pharmacogenetic studies of the response of refractory breathlessness to opioids. This builds on the investigation of other key symptoms for people at the end of life including pain, nausea and cachexia from the same observational cohort. ${ }^{16-18}$

This study tests the null hypothesis that genetic variations in selected candidate SNPs related to opioid receptors, signalling or pain-modifying functions are not associated with the intensity of breathlessness in people already treated with opioids for pain, assuming a similar distribution of pain and breathlessness scores across the population, and that opioid doses had been titrated to clinical effect. Importantly, this study is not exploring SNPs for breathlessness per se, or any relationship between SNPs and response to opioids in breathlessness intensity because of its cross-sectional design, but instead, SNPs which may influence a relationship between breathlessness intensity scores and opioids in people already on opioids for pain.

\section{METHODS}

Methods have been outlined in detail in previous papers from the group. ${ }^{16-18}$

\section{Study setting}

This cross-sectional study included 17 centres from 11 European countries.

In the subgroup of people using morphine with collected breathlessness intensity scores $(n=838), 112$ candidate SNPs in 25 genes (table 1) with a putative influence on opioid receptors, signalling or pain modulation were evaluated for any association with breathlessness intensity scores, controlling for key factors that may influence breathlessness intensity or response to opioids. This analysis was repeated separately for people on fentanyl $(n=405)$ or oxycodone $(n=429)$.

\section{Study participants}

Inclusion criteria were: age 18 years or over; confirmed diagnosis of cancer; and regular use of a WHO step 3 opioid for moderate or severe pain related to the cancer or its treatment for more than 3 days. The only exclusion criterion was the inability to use the language spoken in the treating cancer centre.

\section{Data collection}

Between February 2004 and April 2008, cross-sectional phenotypic data were collected on the cohort including gender, age, weight, height, ethnicity, cancer diagnosis and sites of metastatic disease, the European Organisation for Research and Treatment of Cancer Core Quality of Life Questionnaire (EORTC-QLQ-C30; V.3.0) ${ }^{19}$ and performance status (Karnofsky Performance Status scale).$^{20}$ Data related to opioids included type of opioid, total opioid dose in the $24 \mathrm{~h}$ prior to blood sampling, duration of opioid therapy, and past use of other opioids. Breathlessness intensity was evaluated from question 8 in the EORTC QLQ-C30 on a four-point categorical verbal rating scale (not at all; a little; quite a bit; or very much) covering the person's experience of the symptom over the previous week, reflecting the sensoryperceptual experience of the American Thoracic Society's recent statement on the Mechanisms, Assessment and Management of Dyspnea. ${ }^{21}$

\section{Specimen collection and analysis}

A single specimen of whole blood was collected in an EDTA tube at the time of questionnaire completion and stored at $-80^{\circ} \mathrm{C}$ before batched shipping to the HUNT Biobank in Levanger, Norway. DNA was extracted using Puregene blood kit (Qiagen Science, Germantown, Maryland, USA) and using technology from Applied Biosystems (Foster City, California, USA): the genotyping was done using the SNPlex (dry DNA) Genotyping System; capillary electrophoresis; gene mapping (V.4.0 software); and two SNPs (rs4680 and rs1045642) were extracted using TaqMan SNP allelic discrimination.

\section{Data analysis}

Separate analyses were conducted for each of three mutually exclusive populations (those who were prescribed only one opioid: morphine, oxycodone, or fentanyl), and for each of four modes of inheritance (dominant, recessive, codominant and overdominant). For each population, SNPs that were not in Hardy-Weinberg equilibrium, or had minor allele frequencies $(<5 \%)$ were removed from the analysis, leaving 
Table 1112 Predefined candidate single nucleotide polymorphisms (SNPs) in 25 genes with a putative influence on opioid receptors, signalling and pain modulation: OPRM1, OPRD1, OPRK1, ARRB2, GNAZ, HINT1, Stat6, ABCB1, COMT, HRH1, ADRA2A, MC1R, TACR1, GCH1, DRD2, DRD3, HTR3A, HTR3B, HTR2A, HTR3C, HTR3D, HTR3E, HTR1A, UGT2B7 or CNR1

\begin{tabular}{|c|c|c|c|}
\hline & Morphine $(n=838)$ & Fentanyl $(n=405)$ & Oxycodone $(n=429)$ \\
\hline Age (years) & $62.1(12.1)$ & $63.5(12.6)$ & $62.3(12.3)$ \\
\hline Female gender & $394(47.0)$ & $202(49.9)$ & $188(43.8)$ \\
\hline Body mass index $\left(\mathrm{kg} / \mathrm{m}^{2}\right)$ & $24.1(4.7)$ & $23.2(4.6)$ & $23.9(4.3)$ \\
\hline Karnofsky* & $60(50-70)$ & $60(40-70)$ & $70(50-80)$ \\
\hline Time on opioids (months) & $1(0-4)$ & $1(0-4)$ & $1(0-4.5)$ \\
\hline 24 hourly opioid dose* & $60 \mathrm{mg}(40-120 \mathrm{mg})$ & $50 \mu \mathrm{g}(25-75 \mu \mathrm{g})$ & $60 \mathrm{mg}(40-120 \mathrm{mg})$ \\
\hline
\end{tabular}

The population characteristics of the three cohorts of patients on opioids in the European Palliative Outcomes Study (mean (SD), median $\left(\mathrm{IQR}^{\star}\right)$ or $\left.\mathrm{n}(\%)\right)$.

${ }^{\star} \mathrm{IQR}=($ Lower quartile-upper quartile).

112, 105 and 104 SNPs of interest in each of the morphine, oxycodone and fentanyl populations, respectively. Univariable associations between each SNP and the fourpoint categorical rating scale for breathlessness were determined using Fisher's exact test. To control the overall family-wise type I error rate (FWE) within each mode of inheritance and for each opioid, we used Benjamini-Hochberg (BH) multiple hypothesis testing with a false discovery rate (FDR) set at $20 \%{ }^{22}$

The associations between breathlessness and any SNPs identified as significant using the $\mathrm{BH}$ procedure, within each mode of inheritance and each opioid prescribed, were then examined using multivariable ordinal logistic regression, clustering over country, and adjusting for age, gender, BMI, Karnofsky status, time on opioids, opioid dose, pain levels and the SNPs identified by the $\mathrm{BH}$ procedure. In order to fit the model, it was necessary to remove extraneous SNPs in high linkage disequilibrium, with $\mathrm{D}^{\prime}>0.95$. $^{23}$ The model reported did not violate the proportional odds assumption for any of the three opioids studied. For these analyses, a $p$ value less than 0.05 (two-tailed) is considered statistically significant.

All analyses were conducted using Stata V.13.1 (Statacorp, Texas, USA).

A properly constituted Research Ethics Committee at each participating site approved the study, and each participant provided written, informed consent.

The study is reported according to the STrengthening the REporting of Genetic Association Studies (STREGA) guidelines. $^{24}$

\section{RESULTS}

The clinico-demographic factors for the 1672 participants in this substudy are outlined in table 1 for the cohorts taking each of the three opioids.

Eight hundred and thirty-eight people were taking morphine in whom viable samples were available for 588 . For these people, four variants on the $\beta 2$ arrestin gene (ARRB2) and one on the 5-hydroxytryptamine type 3B (HTR3B rs7103572) gene were associated in univariable analyses with breathlessness intensity (table 2). The genotypic frequency of each variant is also outlined (table 2). Additionally, morphine dose and worsening functional (Karnofsky) status were significantly associated with more intense breathlessness in univariable analyses (table 3). In the multivariable model, three of the ARRB2 variants were excluded as all variants were in high linkage disequilibrium with Lewontin's ${ }^{25}$ normalised linkage disequilibrium parameter $\mathrm{D}^{\prime}>0.95$ for each pair of SNPs (where a value of $\mathrm{D}=0$ indicates independence and $\mathrm{D}=1$ complete dependence of SNP frequencies).

Significance was only maintained for the HTR $3 B$ (rs7103572) and functional status (table 3). There was no interaction between HTR3B (rs7103572) and opioid dose. There were no significant findings in the oxycodone or fentanyl cohorts.

The HTR3B (rs7103572) genotype frequency (TT) was $8.2 \%$ of participants, with $52.8 \% \mathrm{CC}$ and $39.1 \% \mathrm{CT}$. The allele frequency was $72.3 \%(\mathrm{C})$ and $27.7 \%(\mathrm{~T})$. Other HTR3B SNPs tested included rs11214763, rs11606194, rs1176744, rs2276307, rs3782025, rs1672717 and rs7943062.

Table 2 The significant single nucleotide polymorphisms for the recessive mode of inheritance for morphine users (Fisher's exact test) and the frequency of these minor alleles

\begin{tabular}{llll}
\hline Morphine & $\mathbf{p}$ Value & Variant & $\mathbf{n}(\%)$ \\
\hline ARRB2_rs3786047 & 0.0010 & AA vs (AG+GG) & $77(9.6)$ \\
ARRB2_rs2036657 & 0.0045 & GG vs (AG+AA) & $79(9.9)$ \\
ARRB2_rs2271167 & 0.0052 & AA vs (AG+GG) & $77(9.9)$ \\
ARRB2_rs1045280 & 0.0069 & CC vs (CT+TT) & $81(10.1)$ \\
HTR3B_rs7103572 & 0.0070 & TT vs (CC+TC) & $48(8.2)$ \\
\hline
\end{tabular}


Table 3 Association between breathlessness and confounders for the recessive mode of inheritance in the morphine population

\begin{tabular}{|c|c|c|c|c|}
\hline & \multicolumn{2}{|l|}{ Univariable analysis } & \multicolumn{2}{|c|}{ Multivariable analysis } \\
\hline & OR (95\% Cl) & p Value & $\overline{\text { OR }}$ & p Value \\
\hline HTR3B_rs7103572 & 2.86 (1.31 to 6.21$)$ & 0.008 & 2.86 (1.46 to 5.62$)$ & 0.002 \\
\hline ARRB2_rs1045280 & 0.846 (0.59 to 1.22$)$ & 0.36 & $0.97(0.62$ to 1.62$)$ & 0.89 \\
\hline Age (per year) & $1.00(0.99$ to 1.01$)$ & 0.90 & $1.00(0.98$ to 1.02$)$ & 0.73 \\
\hline Male gender & $1.05(0.84$ to 1.31$)$ & 0.69 & $1.06(0.78$ to 1.45$)$ & 0.70 \\
\hline Body mass index (per $1 \mathrm{~kg} / \mathrm{m}^{2}$ ) & 1.03 (0.98 to 1.08$)$ & 0.32 & 1.03 (0.97 to 1.09$)$ & 0.39 \\
\hline Karnofsky status (per 1 point) & $0.83(0.75$ to 0.92$)$ & $<0.001$ & $0.83(0.72$ to 0.96$)$ & 0.011 \\
\hline Time on opioids (per month) & 0.99 (0.97 to 1.00$)$ & 0.17 & $0.99(0.97$ to 1.00$)$ & 0.15 \\
\hline Morphine daily dose (per $100 \mathrm{mg}$ increments) & $1.00(1.00$ to 1.00$)$ & 0.17 & $1.00(1.00$ to 1.00$)$ & 0.469 \\
\hline Pain & 1.19 (1.03 to 1.39$)$ & 0.022 & $1.13(0.84$ to 1.52$)$ & 0.41 \\
\hline
\end{tabular}

\section{DISCUSSION}

In this study, people taking morphine for cancer pain and with both rs7103572 allele variants of the $5 H T 3 B$ gene were three times more likely to have more intense breathlessness having controlled for other available factors. This finding was not mirrored in those taking oxycodone or fentanyl.

Breathlessness, like pain, is a phenotype with complex biological interactions. ${ }^{16}$ Studies have shown only weak associations between the underlying aetiology of breathlessness, the descriptors of sensation and a tailored treatment for breathlessness. ${ }^{26}$ The degree of physiological impairment (such as hypoxaemia or forced expiratory volume in $1 \mathrm{~s}$ ) and a person's subjective sensation of breathlessness are weakly correlated and do not explain much of the interindividual and intraindividual variations observed with the subjective sensation of breathlessness. ${ }^{27}$ Therefore, other factors need to be identified that help to understand the variations in the benefits and toxicities of people's clinical responses. Identifying potential factors associated with response, such as the $H T R 3 B$, has the potential to help reconcile clinical experience with objective factors that explain population differences. It is likely that several factors contribute to the reported threefold variation in breathlessness response to morphine observed in the dose titration study. ${ }^{11}$ Other, as yet unknown factors, must be contributing to this variation in response to opioids, so any factor that helps to unravel variations in response of breathlessness to opioids is likely to be of value to clinicians and researchers given the paucity of such factors currently. These current findings of one potential SNP would form the basis of a prospective study in which opioids were introduced to people with refractory breathlessness in order to determine if this SNP could be used to predict response.

Are these findings biologically plausible? The HTR3B gene is responsible for the synthesis of the serotonergic 5 -hydroxytryptamine $(5 \mathrm{HT})_{3 \mathrm{~B}}$ subtype receptor. There is at least one potential explanation of how opioids may influence the serotonergic system. The original recognition that there was more than one $5 \mathrm{HT}$ receptor was, in part, by demonstrating that morphine was a weak 5HT receptor antagonist, ${ }^{28}$ and was initially, therefore, named the ' $\mathrm{M}$ ' variant. Cocaine and methadone were simultaneously identified as weak 5HT antagonists. ${ }^{28}$ Recently, the $\mathrm{M}$ variant was recognised as the $5 \mathrm{HT}_{3}$ receptor. ${ }^{29}$ Even recent work has now identified five variants of $5 \mathrm{HT}_{3}$ receptors, the most prevalent of which are $\mathrm{A}$ and $\mathrm{B}$. The gene coding for $5 \mathrm{HT}_{3 \mathrm{~B}}($ HTR3B $)$ is found on chromosome 11. The $5 \mathrm{HT}_{3 \mathrm{~B}}$ receptors are found throughout the brain except the cerebellum. ${ }^{30}$ While morphine is an inhibitor of the orthosteric ligand binding site of the $5 \mathrm{HT}_{3}$ ion channel complex, by contrast, fentanyl appears not to have an effect on $5 \mathrm{HT}_{3}$ receptors. ${ }^{31}$ It is therefore biologically plausible that genetic variations in $5 \mathrm{HT}_{3 \mathrm{~B}}$ may variably modulate morphine-related changes in breathlessness perception while fentanyl has no effect. This hypothesis also supports a recent study showing that another SNP of $H T R 3 B$, rs227607 is associated with myalgia score in statin users. ${ }^{32}$

Worsening performance status was the only other factor that was associated with more intense breathlessness in the multivariable analyses. Previous populationbased studies have demonstrated worsening breathlessness as functional status deteriorates, ${ }^{33}$ even in the absence of demonstrable cardiorespiratory disease. ${ }^{5}$ For some patients, it appears that breathlessness is induced by a physical inability to breathe because of the loss of respiratory muscles. ${ }^{34}$

This is a study in a large clinical population using opioids for pain where a range of symptoms were recorded. Symptom assessment used validated tools, ${ }^{19}$ although any interaction between symptoms is poorly understood. ${ }^{35}$ The study relies on a Likert scale for measuring breathlessness. Widely used assessment tools including EORTC QLQC 30 and 15, and the Functional Assessment Cancer Treatment tools use Likert scales as their measure. ${ }^{34} 36$ Symptoms are measured over the last week using EORTC QLQ C-30, but medications reported over the last $24 \mathrm{~h}$. It is unlikely that this difference has a material effect on the relationship being sought in this exploratory study. Although visual analogue scales, or 
Borg scales, may be preferable in this population, Likert scales for reviews of large numbers of symptoms are a reasonable approach. ${ }^{37}$ It is also worth noting that these screening tools make no distinction between the affective component of breathlessness (unpleasantness) and its intensity (severity). ${ }^{27}$ Any prospective study would need to separate these two components of breathlessness and reflect the person's emotional response.

\section{Strengths of the study}

Many genetic association studies have not been reproducible. By contrast, the current study has several key strengths that increase confidence in the finding that a particular SNP might influence morphine-induced modulation of the sensation of breathlessness:

- A plausible biological mechanism;

- Large number of patients (including enough to include relevant clinical and demographic covariates in the analytic models);

- A study population broadly representative of people with advanced cancer;

- A large number of genes and candidate SNPs;

- Rigorous statistical methods to deal with the problem of multiplicity;

- Seeking a signal that is sufficient to be clinically meaningful;

- Use of well-validated assessment tools in rigorously translated versions for the participating countries.

\section{Limitations}

The study did not specify a particular mode of inheritance as primary, and therefore, our results do not control the FWE within the population. The study addressed this by creating sensitivity analyses that aggregated all comparisons for different modes of inheritance with each population and applied the $\mathrm{BH}$ procedure for multiple comparisons. As such, the study did not find any other significant SNPs until the FDR was set at 50\% or greater.

This study only explored individual candidate SNPs and did not explore gene-gene interactions. A negative result does not rule out important SNPs on other parts of candidate genes or on other genes. The study does not contribute to candidate SNPs for the perception of breathlessness itself, only the degree of perception of breathlessness while on opioids for pain.

The change in symptom severity in this cross-sectional study population is unknown, and we are therefore unable to draw conclusions about breathlessness response to opioids. Only longitudinal studies before and after the introduction of opioids for breathlessness can fully answer this question. Some respondents with breathlessness may have partially responded to opioids for the intensity of their breathlessness, and be much worse without them, others may not have responded to opioids at all, and yet others with no breathlessness may have had none prior to starting opioids.

\section{Implications for further research}

There is a need to replicate these findings in a similar independent cohort. There would be an argument for using one of the newer, more comprehensive measures of breathlessness that includes measures of severity, unpleasantness and the person's emotional response. ${ }^{38}{ }^{39}$ Using such measurement tools would allow for a more nuanced exploration of the response to opioids for breathlessness.

Genome-wide association studies may identify genetic variations that are important in the explanation of varying responses of breathlessness to opioids as these studies become more affordable.

\section{CONCLUSIONS}

This large, exploratory study identified one SNP associated with higher levels of breathlessness in people taking morphine for pain, but not in those taking fentanyl or oxycodone. The study does not help to understand any genetic variations associated with the perception of breathlessness per se, but provides a candidate SNP for further evaluation in prospective studies of people before and after morphine is introduced to reduce the perception of breathlessness.

\section{Author affiliations}

${ }^{1}$ Discipline, Palliative and Supportive Services, School of Health Sciences, Flinders University, Bedford Park, South, Australia

${ }^{2}$ Southern Adelaide Palliative Services, Repatriation General Hospital, Adelaide, South Australia, Australia

${ }^{3}$ School of Medicine, Flinders University, Adelaide, South Australia, Australia ${ }^{4}$ University of Lund, Lund, Sweden

${ }^{5}$ Department of Cancer Research and Molecular Medicine, Medical Faculty, Norwegian University of Science and Technology, Trondheim, Norway

${ }^{6}$ Department of Oncology, St Olav's University Hospital, Trondheim, Norway

${ }^{7}$ Hull York Medical School, The University of Hull, Hull, UK

${ }^{8}$ Discipline of Pharmacology, University of Adelaide, School of Medical Sciences, Adelaide, South Australia, Australia

${ }^{9}$ Department of Circulation and Medical Imaging, Medical Faculty, Norwegian University of Science and Technology, Trondheim, Norway

${ }^{10}$ Department of Anaesthesia and Intensive Care Medicine, St Olav's University Hospital, Trondheim, Norway

Acknowledgements The authors thank all the participating sites; the investigators in the main study; the Norwegian University of Science and Technology (NTNU); and all the people who gave their time and energy to create this unprecedented data set. They also thank Dr Ying-Xian Pan for his insightful comments on the manuscript.

Contributors DC and MJ did the literature search. DC, PK and AS provided the study design. SK and PK collected the data. SQ, AS, PK, MJ and DC performed the data analysis. All authors assisted in the data interpretation, writing and final approval of the manuscript.

Funding Funding for the specimen collection and the genetic evaluation was granted through the European Palliative Care Research Collaborative, the Norwegian Research Council, the Norwegian University of Science and Technology and the European Union's Sixth Framework (contract number 037777).

Competing interests None declared.

Ethics approval Research Ethics Committee of each participating site.

Provenance and peer review Not commissioned; externally peer reviewed.

Data sharing statement These data are made available to researchers on request to the European Palliative Care Research Network which is 
responsible for the European Pharmacogenetic Opioid Study coordinated through Trondheim University, Norway. pal.kleptstad@ntnu.no Data on all 2294 participants is available in an annotated database.

Open Access This is an Open Access article distributed in accordance with the Creative Commons Attribution Non Commercial (CC BY-NC 4.0) license, which permits others to distribute, remix, adapt, build upon this work noncommercially, and license their derivative works on different terms, provided the original work is properly cited and the use is non-commercial. See: http:// creativecommons.org/licenses/by-nc/4.0/

\section{REFERENCES}

1. Currow DC, Plummer JL, Crockett A, et al. A community population survey of prevalence and severity of dyspnea in adults. J Pain Symptom Manage 2009;38:533-45.

2. Frostad A, Soyseth V, Haldorsen T, et al. Respiratory symptoms and $30 y e a r$ mortality from obstructive lung disease and pneumonia. Thorax 2006:61:951-6.

3. Solano JP, Gomes B, Higginson IJ. A comparison of symptom prevalence in far advanced cancer, AIDS, heart disease, chronic obstructive pulmonary disease and renal disease. J Pain Symptom Manage 2006;31:58-69.

4. Bowden JA, To TH, Abernethy AP, et al. Predictors of chronic breathlessness: a large population study. BMC Public Health 2011;11:33

5. Currow D, Smith J, Davidson P, et al. Do the trajectories of dyspnea differ in prevalence and intensity by diagnosis as the end of life? A consecutive cohort study. J Pain Symptom Manage 2010;39:680-90.

6. Steinhauser KE, Christakis NA, Clipp EC, et al. Factors considered important at the end of life by patients, family, physicians, and other care providers. JAMA 2000;284:2476-82.

7. Mahler DA, Murray JA, Waterman LA, et al. Endogenous opioids modify dyspnoea during treadmill exercise in patients with COPD. Eur Respir J 2009;33:771-7.

8. Gifford AH, Mahler DA, Waterman LA, et al. Neuromodulatory effect of endogenous opioids on the intensity and unpleasantness of breathlessness during resistive load breathing in COPD. COPD 2011;8:160-6.

9. Banzett RB, Adams L, O'Donnell CR, et al. Using laboratory models to test treatment: morphine reduces dyspnea and hypercapnic ventilatory response. Am J Respir Crit Care Med 2011;184:920-7.

10. Abernethy AP, Currow DC, Frith $\mathrm{P}$, et al. Randomised, double blind, placebo controlled crossover trial of sustained release morphine for the management of refractory dyspnoea. BMJ 2003;327:523-8.

11. Currow DC, McDonald C, Oaten S, et al. Once-daily opioids for chronic dyspnea: a dose increment and pharmacovigilance study. $J$ Pain Symptom Manage 2011;42:388-99.

12. Jennings AL, Davies AN, Higgins JP, et al. A systematic review of the use of opioids in the management of dyspnoea. Thorax 2002;57:939-44.

13. Johnson MJ, Bland JM, Oxberry SG, et al. Clinically important differences in the intensity of chronic refractory breathlessness. $J$ Pain Symptom Manage 2013;46:957-63.

14. Ekstrom MP, Bornefalk-Hermansson A, Abernethy AP, et al. Safety of benzodiazepines and opioids in very severe respiratory disease: national prospective study. BMJ 2014;348:g445.

15. Johnson MJ, Bland JM, Oxberry SG, et al. Opioids for chronic refractory breathlessness: patient predictors of beneficial response. Eur Respir J 2013;42:758-66.

16. Klepstad P, Fladvad T, Skorpen F, et al, European Palliative Care Research Collaborative (EPCRC); European Association for Palliative Care Research Network. Influence from genetic variability on opioid use for cancer pain: a European genetic association study of 2294 cancer pain patients. Pain 2011;152:1139-45.
17. Laugsand EA, Fladvad T, Skorpen F, et al. Clinical and genetic factors associated with nausea and vomiting in cancer patients receiving opioids. Eur J Cancer 2011;47:1682-91.

18. Solheim TS, Fayers PM, Fladvad T, et al. Is there a genetic cause of appetite loss?-an explorative study in 1,853 cancer patients. $J$ Cachexia Sarcopenia Muscle 2012;3:191-8.

19. Aaronson NK, Ahmedzai S, Bergman B, et al. The European Organization for Research and Treatment of Cancer QLQ-C30: a quality-of-life instrument for use in international clinical trials in oncology. J Natl Cancer Inst 1993;85:365-76.

20. Jones R Jr, Zubrod CG, Karnofsky DA, et al. Use of alkylating agents and the future of these agents. Natl Cancer Inst Monogr 1960;3:127-47.

21. Parshall MB, Schwartzstein RM, Adams L, et al. An official American Thoracic Society statement: update on the mechanisms, assessment and management of dyspnea. Am J Resp Crit Care Med 2012;185:435-52.

22. Benjamini $\mathrm{Y}$, Hochberg $\mathrm{Y}$. Controlling the false discovery rate: a practical and powerful approach to multiple testing. J R Stat Soc $B$ (Methodol) 1995:289-300.

23. Lewontin R. The interaction of selection and linkage. I. General considerations; heterotic models. Genetics 1964;49:49-67.

24. Little J, Higgins JP, loannidis JP, et al. STrengthening the REporting of Genetic Association Studies (STREGA) - an extension of the STROBE statement. Genet Epidemiol 2009;33:581-98.

25. Lewontin RC. On measures of gametic disequilibrium. Genetics 1988;120:849-52.

26. Williams $\mathrm{M}$, Cafarella $\mathrm{P}$, Olds $\mathrm{T}$, et al. The language of breathlessness differentiates between patients with COPD and age-matched adults. Chest 2008;134:489-96.

27. Williams M, Cafarella $\mathrm{P}$, Olds $\mathrm{T}$, et al. Affective descriptors of the sensation of breathlessness are more highly associated with severity of impairment than physical descriptors in people with COPD. Chest 2010;138:315-22.

28. Gaddum JH, Picarelli ZP. Two kinds of tryptamine receptor. $\mathrm{Br} \mathrm{J}$ Pharmacol Chemother 1957:12:323-8.

29. Eglen RM, Swank SR, Walsh LK, et al. Characterization of 5-HT3 and 'atypical' 5-HT receptors mediating guinea-pig ileal contractions in vitro. Br J Pharmacol 1990;101:513-20.

30. Hammer C, Cichon S, Muhleisen TW, et al. Replication of functional serotonin receptor type $3 \mathrm{~A}$ and $\mathrm{B}$ variants in bipolar affective disorder a European multicenter study. Trans/ Psychiatry 2012;2:e103.

31. Walstab J, Rappold G, Niesler B. 5-HT(3) receptors: role in disease and target of drugs. Pharmacol Ther 2010;128:146-69.

32. Ruano G, Thompson PD, Windemuth A, et al. Physiogenomic association of statin-related myalgia to serotonin receptors. Muscle Nerve 2007;36:329-35.

33. Seow H, Barbera L, Sutradhar R, et al. Trajectory of performance status and symptom scores for patients with cancer during the last six months of life. J Clin Oncol 2011;29:1151-8.

34. Dudgeon DJ, Lertzman M. Dyspnea in the advanced cancer patient. $J$ Pain Symptom Manage 1998;16:212-19.

35. Kirkova J, Walsh D, Aktas A, et al Cancer symptom clusters: old concept but new data. Am J Hosp Palliat Care 2010;27:282-8.

36. Cella DF, Tulsky DS, Gray G, et al. The Functional Assessment of Cancer Therapy scale: development and validation of the general measure. J Clin Oncol 1993;11:570-9.

37. Grant S, Aitchison T, Henderson E, et al. A comparison of the reproducibility and the sensitivity to change of visual analogue scales, Borg scales, and Likert scales in normal subjects during submaximal exercise. Chest 1999:116:1208-17.

38. Yorke J, Moosavi SH, Shuldham C, et al. Quantification of dyspnoea using descriptors: development and initial testing of the Dyspnoea-12. Thorax 2010;65:21-6.

39. Banzett R, O'Donnall C, Guilfoyle T, et al. Multidimensional Dyspnea Profile: an instrument for clinical and laboratory research. Eur Respir $J$ 2015. Published Online First 18 Mar 2015. doi:10.1183/ 09031936.00038914 